\title{
Assessing Socioeconomic Drought Based on a Standardized Supply and Demand Water Index
}

Jiawei Zhou

Sun Yat-Sen University

Xiaohong Chen ( $\nabla$ eescxh@mail.sysu.edu.cn )

Sun Yat-Sen University

Chuang Xu

Sun Yat-Sen University

Pan Wu

Sun Yat-Sen University

\section{Research Article}

Keywords: Socioeconomic drought, Standardized Supply and Demand Water Index, Copulas, Joint return period, Jianjiang River basin

Posted Date: January 14th, 2022

DOl: https://doi.org/10.21203/rs.3.rs-993692/v1

License: (c) (7) This work is licensed under a Creative Commons Attribution 4.0 International License. Read Full License

Version of Record: A version of this preprint was published at Water Resources Management on April 1st, 2022. See the published version at https://doi.org/10.1007/s11269-022-03117-0. 
1 Assessing socioeconomic drought based on a standardized supply and demand

2 water index

3 Jiawei Zhou,Xiaohong Chen*,Chuang Xu,Pan $\mathrm{Wu}$

4 Center for Water Resources and Environment Research, School of Civil Engineering,

5 Sun Yat-sen University, Guangzhou, China

$6 \quad *$ Correspondence to: Xiaohong Chen (eescxh@mail.sysu.edu.cn)

7 Abstract: Socioeconomic drought is a phenomenon of water shortage caused by an

8 imbalance between the supply and demand of water resources in natural and human

9 socioeconomic systems. Occurrence of these droughts is closely related to sustainable

10 socioeconomic development. However, compared with meteorological drought,

11 hydrological drought and agricultural drought, socioeconomic drought has received

12 relatively little attention. Therefore, this paper proposes a universal and relatively

13 simple socioeconomic drought assessment index, the Standardized Supply and Demand

14 Water Index (SSDWI). Taking the Jianjiang River Basin (JJRB) in Guangdong Province,

15 China as an example, socioeconomic drought characteristics and trends during 1985-

162019 were analyzed. The return period of different levels of drought were calculated

17 using a copula function to estimate the risk of socioeconomic drought in the basin, and

18 the relationship between socioeconomic, meteorological, and hydrological droughts

19 and their potential drivers were discussed. The results showed that: (1) SSDWI was a

20 better index for characterizing socioeconomic drought in the JJRB. 29 socioeconomic

21 droughts occurred in the basin during the past 35 years, with an average duration of 
6.16 months and an average severity of 5.82 per events. Socioeconomic droughts mainly occurred in autumn and winter, which also had more severe droughts than other seasons. (2) In the JJRB, the joint return periods of ' $\square$ ' and ' $\cap$ ' for moderate drought, severe drought and extreme drought were $8.81 \mathrm{a}$ and 10.81a, 16.49a and 26.44a, and 41.68a and 91.13a, respectively; (3) Due to the increasing outflow from Gaozhou Reservoir, the risk of socioeconomic drought and hydrological drought in the JJRB has significantly declined since 2008. The reasonable operation of the reservoir has played an important role in alleviating the hydrological and socioeconomic drought in the basin.

Keywords: Socioeconomic drought, Standardized Supply and Demand Water Index, Copulas, Joint return period, Jianjiang River basin

\section{Introduction}

Drought is a complex natural disaster that depends on a variety of influencing factors, but stems primarily from insufficient precipitation for prolonged periods. Droughts have large impacts on normal water supplies, crop irrigation, ecological environment and subsequently can affect people's lives and threaten property safety (Wilhite, 2000; Trenberth, 2001;Mishra and Singh, 2010; Stoll et al., 2011; Yoo et al., 2016; Cammalleri et al., 2017;Fang et al., 2019a). There are four types of drought: meteorological, hydrological, agricultural and socioeconomic (Wilhite and Glantz,1985; American Meteorological Society, 2004; World Meteorological Organization, 2006). Socioeconomic drought occurs when water demand exceeds water supply and consequently causes various social, economic and ecological problems (Dinar and 
Mendelsohn, 2011; Hayes et al., 2011;Vandenberghe et al., 2011; Zseleczky and Yosef, 2014; Ren et al., 2019). Among the drought types, socioeconomic drought is the only one driven by unnatural factors (Tu et al., 2018). With the growth of populations and industries, regional water demands have increased and socioeconomic drought has become a major problem facing the economic development of many countries and regions of the world. (Arab et al., 2010; L.P.H. van Beek et al., 2011; Yoshihide Wada et al., 2011; Madani, 2014; Sivapalan, 2015; Wheater and Gober, 2015; Vogel et al., 2015; Montanari, 2015).

In general, drought indices are the most powerful tools available for studying the various types of drought events. Over the past decades, a variety of new indices have been proposed and used to study different drought issues. Commonly used indices include Palmer's drought severity index(PDSI; Palmer, 1965), surface water supply index (SWSI; Shafer and Dezman, 1982), standardized precipitation index (SPI; McKee et al., 1993), vegetation condition index (VCI; Kogan, 1995), standardized runoff index (SRI; Shukla and Wood, 2008), and standardized precipitation evapotranspiration index (SPEI; Vicente-Serrano et al., 2010). The above indices have all been widely used to assess the impact of meteorological drought, hydrological drought, agricultural drought and have proven their superiority and universality as they have been continuously improved and applied. However, in terms of socioeconomic drought, due to relatively recent development of the field, there is still a lack of universally available and simple drought indices.

Under a backdrop of drastic global climate change (Kunkel, 2003;Hanson and 
Weltzin, 2000; Hirabayashi et al., 2008; Ahn et al., 2016; Mehran et al., 2015; Tsanis \& Tapoglou, 2019; Vicuna et al., 2013;Zhou et al., 2020a, 2020b; Aherne et al., 2006; Tietjen et al., 2017), more and more researchers have focused on the study of socioeconomic drought and a series of indicators to measure socioeconomic drought have been proposed (Eklund \& Seaquist, 2015; Guo et al., 2019a,2019b; Huang et al., 2016; Liu et al., 2020; Mehran et al., 2015; Shi et al., 2018; Tu et al., 2018). These indicators can be divided into two main categories, related to either reservoir resilience or river runoff deficit.

As a main component of artificial infrastructure, reservoirs help address the uneven distribution of water in space and time, and increase a society's ability to resist extreme events (such as floods and droughts). Reservoir management plays an important role in water supply and demand security while also preventing the adverse effects of socioeconomic droughts (Mehran et al.,2015; Bai et al.,2015; Fang et al.,2017). By the end of the last century, about $20 \%$ of the all annual freshwater flow globally was controlled by artificial reservoirs, and $70 \%$ of global freshwater production was supplied by these reservoirs (Fekete et al., 1999; Shiklomanov et al., 2000; Vörösmarty and Sahagian, 2000). These statistics illustrate indicating the importance of reservoirs in providing global human water resilience and their close relationship between reservoirs and human socioeconomic systems (Zhang et al., 2014b; Mehran et al., 2015). Therefore, considering the regulated capacity of reservoirs, Mehran et al.(2015) used multivariate standardized reliability and resilience index (MSRRI) to identify socioeconomic drought events; Huang et al.(2016a) applied the 
MSRRI framework to evaluate socioeconomic drought in the Heihe River Basin, China, and discussed the impacts of El Niño Southern Oscillation (ENSO)/Atlantic and Oscillation (AO) on socioeconomic drought; Zhao et al.(2019) used MSRRI to assess socioeconomic drought of the Datong River and analyzed the meteorological driving force by cross wavelet; Guo et al.(2019) improved the MSRRI framework by combining it with reservoir operational rules, using copula functions to calculate the return periods of different grades of drought in the upper Yellow River while also considering the effects of extreme climate change. This framework can accurately quantify socioeconomic drought situation under the influence of reservoir operation, but it still has some limitations. It is difficult to use this indicator to assess the real socioeconomic drought scenarios for basins or regions that lack reservoirs or have low reservoir storage capacities.

Generally speaking, most of the water supply in a basin is diverted from the river. When the river runoff is less than the minimum required to meet in-stream water demand (as determined by requirements for navigation, ecology, water quality and water use), a socioeconomic drought event can be considered to have occurred. It is also feasible to assess socioeconomic drought from the river runoff deficit perspective. In this way, Shi et al.(2017) proposed the socioeconomic drought index (SEDI) to assess historical and future socioeconomic droughts conditions in the Dongjiang River Basin. Tu et al.(2018) defined socioeconomic drought events by establishing a flow threshold, and discussed the role of reservoir regulation in alleviating socioeconomic drought risk. However, this method is similar to the discriminatory method used for assessing 
hydrological drought, which could be confounded by the fact that, when hydrological drought occurs, there may be no socioeconomic drought.

The concept of 'resilience' is used either from the characteristics of reservoirs or from the deficit of river runoff, especially the SEDI, which specifies that a socioeconomic drought event will not end until all previous water shortages recover from excess water in the subsequent period. Therefore, the duration of socioeconomic drought calculated by this index is usually much longer than other droughts, but this may overestimate the impact of socioeconomic drought events (Liu et al.,2020). In fact, a portion of the previous water deficit may never be recovered, while other portions do not need to be recovered. When drought occurs, watershed management departments usually prioritize ensuring domestic and industrial water supplies, and appropriately reduce agricultural water use (Piao et al., 2010; Shao et al., 2009). Moreover, the limitation of irrigation water during arid periods may not significantly affect the growth of plants as they have physiologically adaptive mechanisms (Ingram \& Bartels,1996). Other water resources (such as groundwater) can also be considered as a backup, and this part of water shortage is almost irreparable when returning to normal water supply. For more extreme cases, where industrial and domestic water is also strained, actions must be taken to shut down industrial production to save water. When the water supply is restored to normal, the domestic and industrial water is restored to normal. The previous part of water shortage does not need to be restored (policy restrictions) or only a small part of water shortage can be restored (Boisson et al., 2014; Paradis et al., 2020; Liu et al., 2020). So it is necessary to explore the characteristics of socioeconomic 
drought without considering recovery and gap-filling.

Drought can be quantified according to the degree of water scarcity, and socioeconomic drought can be quantified as the degree to which water supply does not meet water demand. Referring to the ideas of PDSI, SPEI and other indices, this paper proposes a more universally applicable standardized supply and demand water index (SSDWI) as an indicator to measure socioeconomic droughts. This index first simulates the monthly water supplies and demands within a basin and then uses the difference function to calculate SSDWI. Then the run theory is used to identify socioeconomic drought events, analyze their characteristics at different time scales, and determine the multivariate distribution of drought characteristics using copula functions. Furthermore, the binary joint return period can be calculated to characterize the potential risk of socioeconomic drought. In this study, the Jianjiang River Basin from 1985 to 2019 was taken as an example for calculating the SSDWI and the accompanying characteristics.

Then the relationship between socioeconomic drought and meteorological hydrological drought and its changing trends were discussed along with an analysis of possible causes. The results of this study can provide a new perspective for better understanding of regional socioeconomic drought, and has a high value for decision makers seeking drought prevention and early warning.

\section{Study area and data}

The Jianjiang River Basin (JJRB) is located in the western part of Guangdong Province, China (Figure 1). The Jianjiang River mainly flows through Maoming and 
Wuchuan with an average annual water resources of 8.94 billion $\mathrm{m}^{3}$, making it the largest river in the coastal river system of Guangdong Province. The watershed is located within $110^{\circ} 20^{\prime} \sim 111^{\circ} 20^{\prime} \mathrm{E}$ and $21^{\circ} 15^{\prime} \sim 22^{\circ} 30^{\prime} \mathrm{N}$, at the junction of subtropical monsoon and tropical monsoon regions with a humid climate. The total watershed area is $9464 \mathrm{~km}^{2}$, the annual average temperature is $20-21^{\circ} \mathrm{C}$, and the annual average rainfall is $1780 \mathrm{~mm}$. Gaozhou Reservoir is the most important large reservoir in the basin, with a total catchment area of $1022 \mathrm{~km}^{2}$ and a total reservoir capacity of 1.28 billion $\mathrm{m}^{3}$. Its main functions are water supply, irrigation, power generation and facilitating shipping in the basin. Due to the monsoon climates and uneven spatial and temporal distribution of precipitation, $70 \%$ of the total annual precipitation occurs from April to September, coupled with the strong solar radiation, high temperature, large evaporation and crop transpiration in western Guangdong. Seasonal and regional droughts have occurred frequently, which has become one of the important factors restricting the sustainable development of social economy.

In the JJRB, agriculture represents the largest water demand, accounting for about $65 \%$ of all water usage in the basin. The water supply in the basin comes via water storage (reservoirs) and diversion, which account for about $70 \%$ of all water supplies. The monthly flow data from 1985 to 2019 were collected at Huazhou Station, the main control station of the basin. The measured inflow and outflow data of the Gaozhou Reservoir were also collected. The annual water supply data from 1985 to 2019 were taken from the basin water resources bulletin. The basin water quota, crop effective irrigation area, population, output value and other social and economic data were 

monthly water supply and use data from 2014 to 2019 were taken from the operational

178 data records of waterworks, main canals and reservoirs.

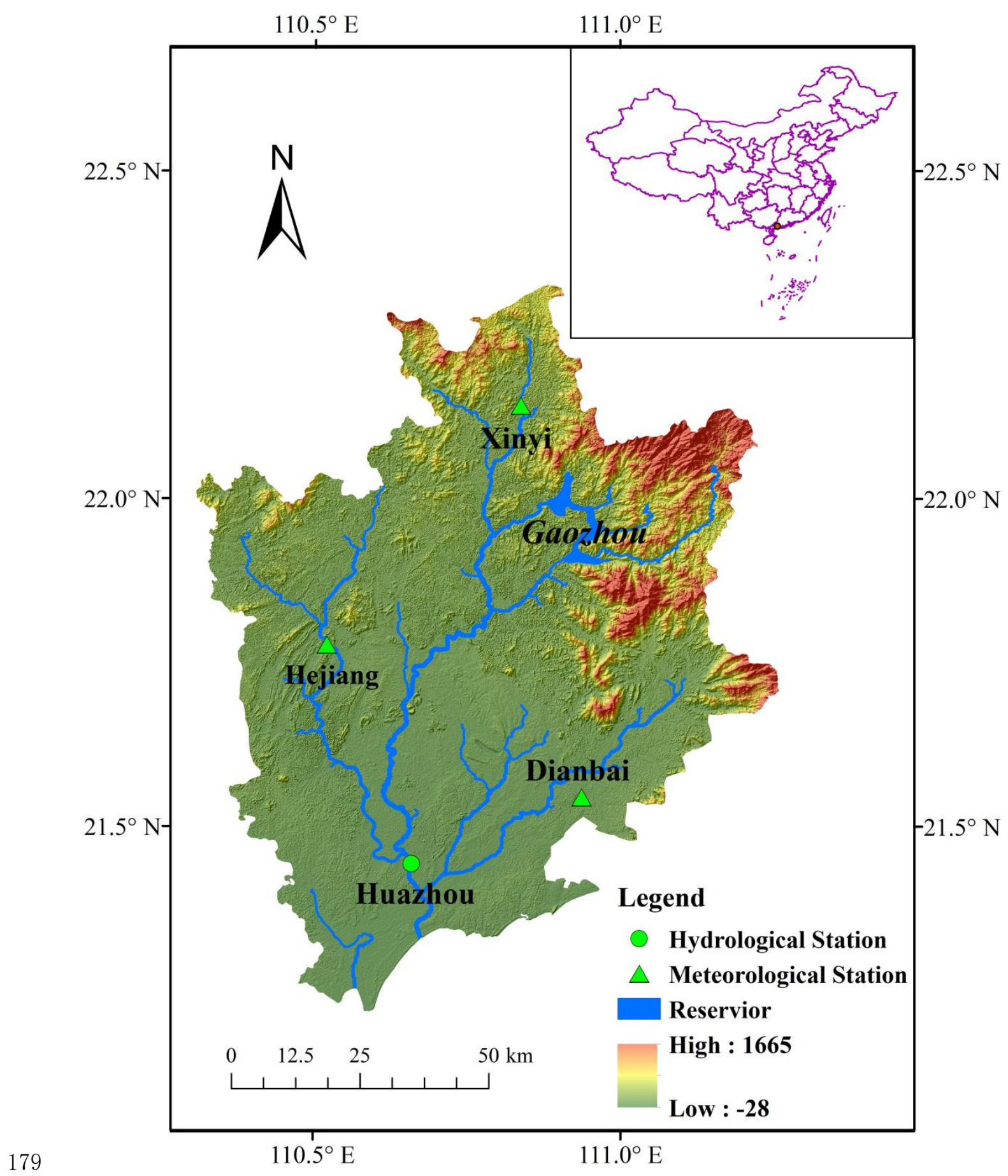

Fig. 1 Water reservoirs and stations in the Jianjiang River Basin, South China 


\section{Methodology}

\subsection{Simulation of water supply and demand}

Socioeconomic drought is a water shortage phenomenon caused by an imbalance between supply of water resources in natural systems and demand of human socioeconomic systems. Therefore, simulated time series of water supply and demand in the basin can be used to characterize the socioeconomic drought to a certain extent. 1985 - 2019 was selected as the research period, and the annual water supply during this period was determined using the water resources bulletin and statistical yearbook of the basin. In the JJRB, the water supply is usually divided into four parts: storage, diversion, withdrawal and groundwater. Due to the lack of data, the intra-annual distribution ratios of different water supply components were estimated based on the monthly water supply data from 2014 to 2019 (Fig. 2 (a)).

Water demand is dominated by agricultural, industrial and domestic components, which are calculated according to the quota method. The main calculation methods are shown in Table 1. The annually allocated proportion of water demand for each component part was determined based on their monthly water consumption in the basin from 2014 to 2019 (Fig. 2 (b)). The relevant data used in the calculation were obtained from the statistical yearbooks and water resource bulletins of local cities.

Table 1 Calculation of annual total water demand in the JJRB

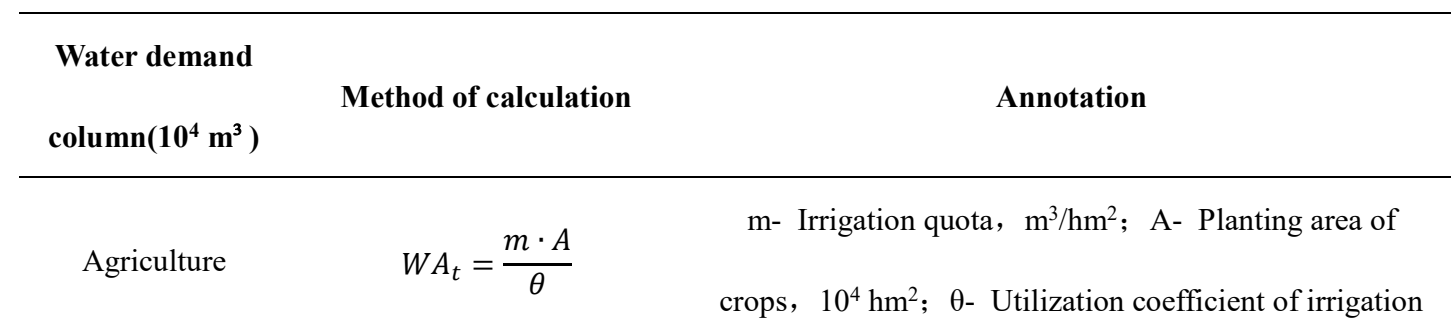


water;

$\mathrm{P}_{1}$ and $\mathrm{P}_{2}$ represent urban and rural population

Life

$W L_{t}=P_{1} k_{1}+P_{2} k_{2}$

respectively; $\mathrm{k}_{1}$ and $\mathrm{k}_{2}$ represent urban and rural domestic

water quota respectively, $\mathrm{m}^{3} /($ p.a)

Y- Total industrial output value, $10^{4}$ yuan; r- Repetition

Industry $\quad W I_{t}=Y(1-r) g \quad$ rate of industrial water; g- Water consumption per $10^{4}$

yuan of industrial output value, $\mathrm{m}^{3} / 10^{4}$ yuan

Total $\quad D_{t}=W A_{t}+W L_{t}+W I_{t}$

$\mathrm{D}_{\mathrm{t}}$-Total annual water demand of basin

201
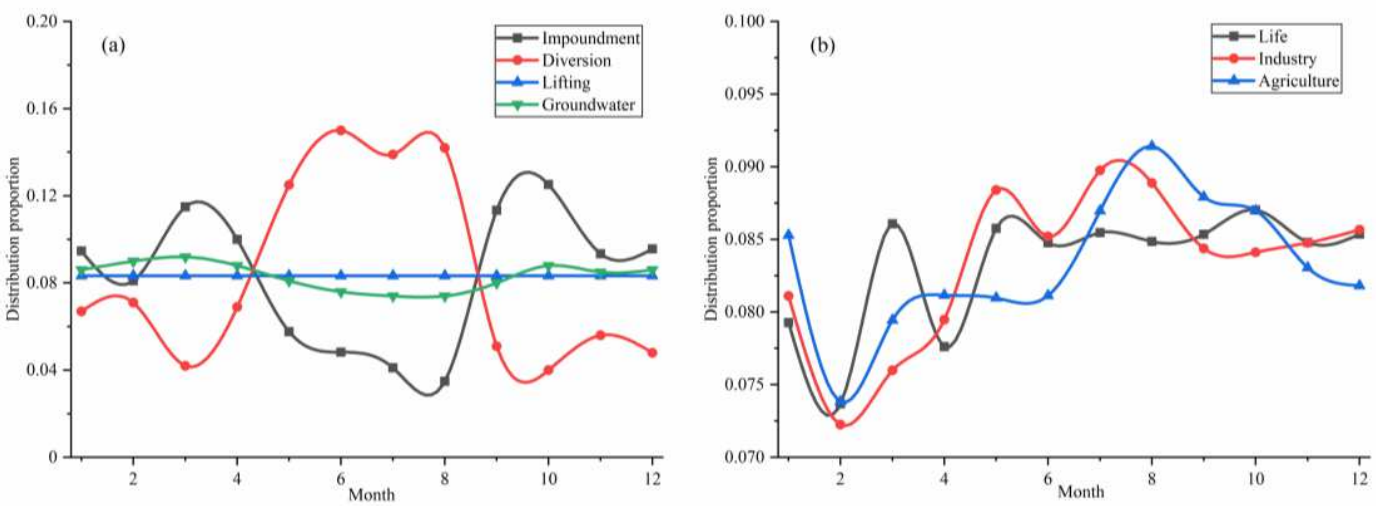

Fig. 2 Distributions of water supply(a) and water demand(b) proportions throughout the year

\subsection{Standardized supply and demand water index}

Since socioeconomic drought is essentially an imbalance between supply and demand of water, the SSDWI can calculated by referring to the methods for the PDSI,

SPEI and other indices that utilize the monthly differences between water supply and demand. First,monthly deficit or surplus is calculated as follows:

$$
X_{i}=S_{i}-D_{i}(i=1,2, \ldots, 12)
$$

211 where, $X_{i}$ represents the monthly deficit or surplus of water; $S_{i}$ represents monthly

212 supply; $D_{i}$ represents monthly demand; and $i$ represent a specific month. This 
calculation can be made for any time scale, like SPI. For subsequent operations, the $\mathrm{X}_{\mathrm{i}}$ sequence is normalized so that its average value is 0 and standard deviation is 1 . For

215 fitting, the normal distribution (Norm), generalized extreme value distribution (GEV),

216 logistic distribution (Log), log-logistic distribution (Log-Log) and log-normal 217 distribution (Log-Norm) were selected (Fig. 3). In the abscissa, 100 indicates a perfect balance between water supply and demand, numbers over 100 indicate a surplus of water, and numbers under 100 indicate that demand exceeds supply, and the difference compared to 100 is the deficit or surplus water $\left(10^{8} \mathrm{~m}^{3}\right)$. At the same time, the
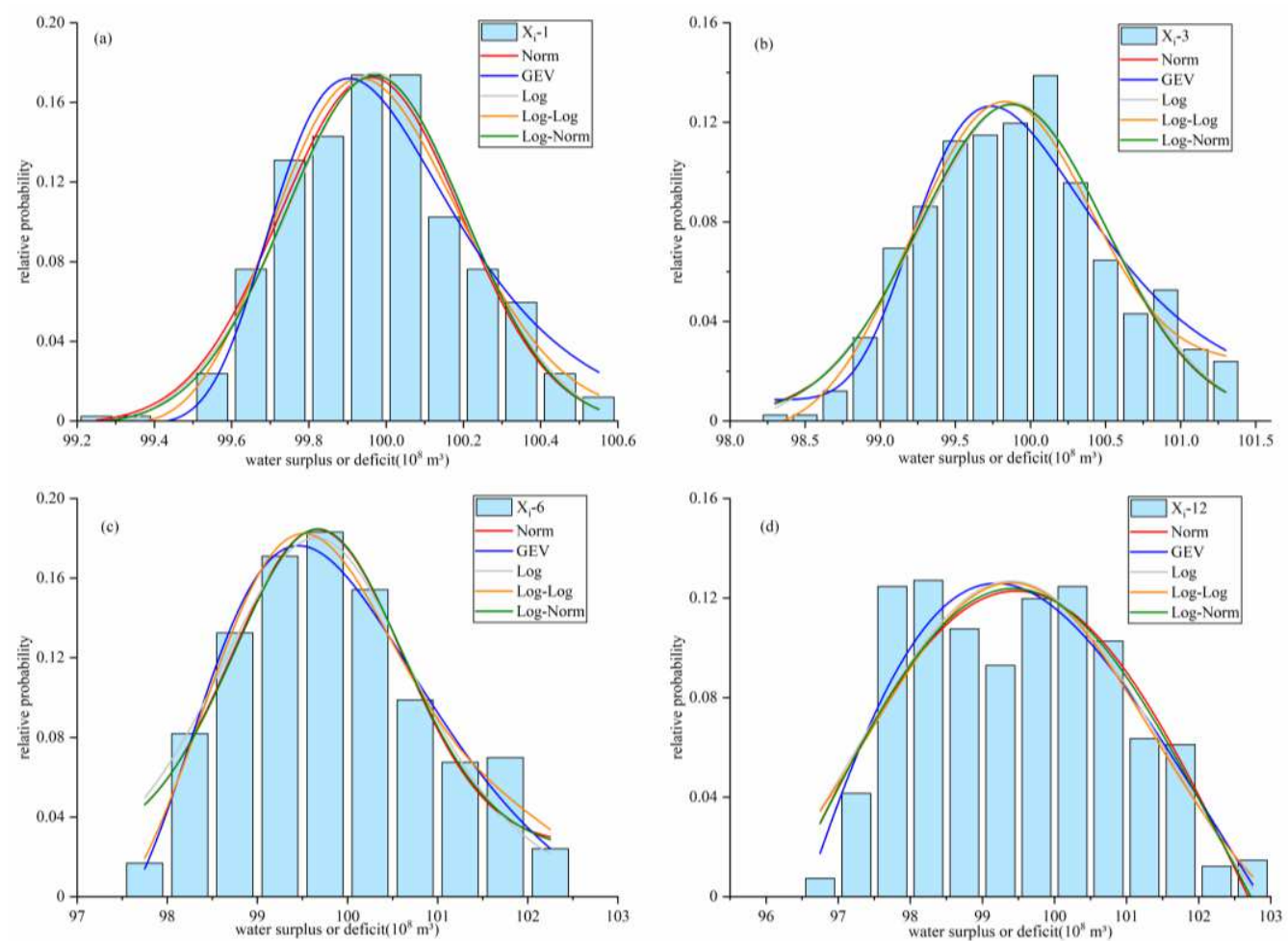

Fig. 3 Empirical values using the normal, GEV, logistic, log-logistic and lognormal distributions of the 


\begin{tabular}{cccccc}
\hline & Norm & GEV & Log & Log-Log & Log-Norm \\
\hline $\mathrm{X}_{\mathrm{i}-1}$ & 0.9187 & 0.9811 & 0.6941 & 0.6204 & 0.4444 \\
$\mathrm{X}_{\mathrm{i}-3}$ & 0.6259 & 0.7765 & 0.3981 & 0.4107 & 0.6129 \\
$\mathrm{X}_{\mathrm{i}-6}$ & 0.8541 & 0.8909 & 0.5215 & 0.4541 & 0.6234 \\
$\mathrm{X}_{\mathrm{i}-12}$ & 0.6017 & 0.6404 & 0.4790 & 0.4425 & 0.5147 \\
\hline
\end{tabular}

GEV distribution function is as follows:

$$
F(x)=\exp \left\{-\left[1+\rho\left(\frac{x-\mu}{\sigma}\right)\right]^{-\frac{1}{\rho}}\right\}
$$

231 where, $\rho$ is the shape parameter, $\mu$ is the unknown parameter, and $\sigma$ is the scale parameter. The three parameters are all estimated by the maximum likelihood method. The SSDWI can easily be obtained as the standardized values of $F(x)$. For example, by following the classical approximation of Abramowitz and Stegun(1965),

$$
\left\{\begin{array}{cc}
S S D W I=W-\frac{C_{0}+C_{1} W+C_{2} W^{2}}{1+d_{1} W+d_{2} W^{2}+d_{3} W^{3}} & F(x) \leq 0.5 \\
S S D W I=-\left(W-\frac{C_{0}+C_{1} W+C_{2} W^{2}}{1+d_{1} W+d_{2} W^{2}+d_{3} W^{3}}\right) & F(x)>0.5
\end{array}\right.
$$

237 where,

$$
W=\left\{\begin{array}{l}
\sqrt{-2 \ln (1-F(x))} \\
\sqrt{-2 \ln F(x)}
\end{array}\right.
$$

$$
\begin{aligned}
& F(x) \leq 0.5 \\
& \quad F(x)>0.5
\end{aligned}
$$

where, $\mathrm{C}_{0}=2.515517, \mathrm{C}_{1}=0.802853, \mathrm{C}_{2}=0.010328, d_{1}=1.432788, d_{2}=0.189269$ and $d_{3}=0.001308$. 


\subsection{Run theory}

In this study, the run theory (Yevjevich, 1967) was used to identify socioeconomic drought events and extract characteristics such as drought duration, severity and intensity. Drought duration is the duration of a drought event from its initiation to end.

Drought severity is the cumulative value of the drought index during the drought event (usually taken as the sum of opposite numbers). The drought intensity is calculated as the ratio of drought severity to drought duration. The specific methods of identifying drought events at the monthly time scale using run theory are as follows (Fig. 4): (1)

Set three truncation levels $\mathrm{X}_{0}=0, \mathrm{X}_{1}=-0.3, \mathrm{X}_{2}=-0.5$ ( $\mathrm{X}$ is the drought index value); (2) when the drought index is less than $X_{1}$, it is preliminarily determined that a drought had occurred in that month; (3) when the drought index is greater than $\mathrm{X}_{2}$, for a drought event lasting one month, it is determined that there was no drought in that month and eliminated; and (4) when the time interval between two adjacent droughts processes is only one month, and the drought index value within that month is less than $\mathrm{X}_{0}$, the two adjacent droughts processes are combined into one drought event. In this last case, the drought duration is the sum of the two drought durations plus one, and the drought severity is the sum of two drought events. Otherwise, it is two independent drought processes.

After extracting the drought characteristics such as duration, severity and intensity, the joint return period under different levels of drought can be calculated using their distribution. 


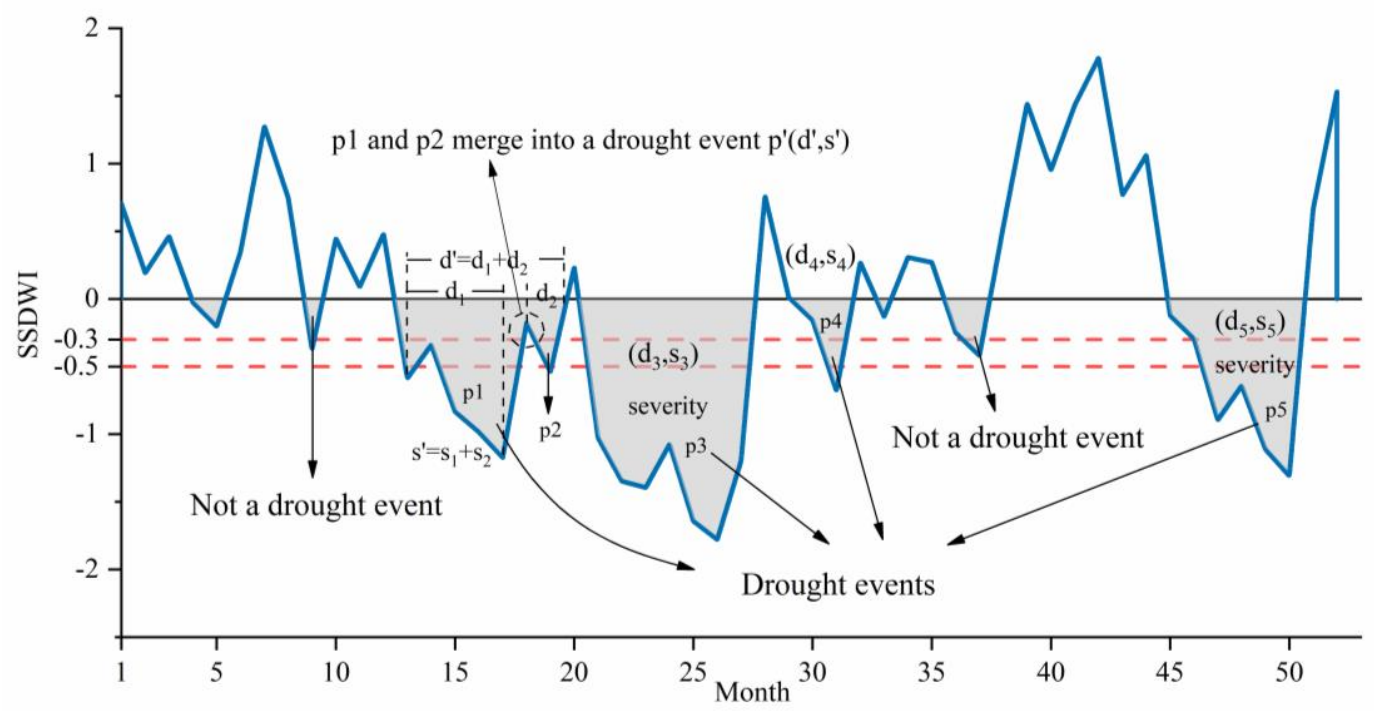

Fig. 4 Identification of socioeconomic drought events and their characteristics using run theory

\subsection{Copulas}

Copula functions are highly recognized and widely used multidimensional joint analysis methods. They take advantage of the fact that each factor does not require a uniform distribution function to be applied in the field of multivariate research. In this paper, we chose the two-dimensional copula function for drought return period analysis, expressed as follows:

$$
C(u, v)=\varphi^{-1}(\varphi(u), \varphi(v))
$$

Where, $\varphi$ denotes the convex function; and $u$ and $v$ represent the two variables.

Generally, there are three main types of copulas: elliptical, Archimedean and quadratic.

The elliptical copula can be used to construct an abnormal extreme relationships, so it is better for describing extreme events. The Archimedean copula is simple to construct and has strong representability. Both elliptical and Archimedean connection functions are widely used in hydrological frequency analysis (Genest et al., 2007; Song and Singh, 
2010; Chen et al., 2015; Reddy and Ganguli, 2012). Therefore, in this study, three

Archimedean copulas and two elliptical copulas were used to simulate the joint probability of marginal distribution of drought duration and severity (Table 3), and the maximum likelihood method was used to estimate the copula parameters (Joe, 1997).

Table 3 Expression and definition domain of the Copula functions

\begin{tabular}{lccc}
\hline \multicolumn{2}{c}{ Copula function } & Expression & $\theta$ Definition \\
\hline Archimed & Clayton & $\max \left[\left(u^{-\theta}+v^{-\theta}-1\right)^{-1 / \theta}, 0\right]$ & $(0,+\infty)$ \\
ean & Frank & $-\frac{1}{\theta} \ln \left[1+\frac{\left(e^{-\theta \mathrm{u}}-1\right)\left(e^{-\theta \mathrm{v}}-1\right)}{e^{-\theta}-1}\right]$ & $\mathrm{R}$ \\
copulas & Gumbel & $\exp \left\{-\left[(-\ln u)^{\theta}+(-\ln v)^{\theta}\right]^{1 / \theta}\right\}$ & {$[1,+\infty)$} \\
elliptical & Gassian & $\int_{-\infty}^{\phi^{-1}(u)} \int_{-\infty}^{\phi^{-1}(v)} \frac{1}{2 \pi \sqrt{1-\theta^{2}}} \exp \left\{-\frac{s^{2}-2 \theta s t+t^{2}}{2\left(1-\theta^{2}\right)}\right\} d s d t$ & $(-1,1)$ \\
copulas & $\mathrm{t}$ & $\int_{-\infty}^{t_{k}^{-1}(u)} \int_{-\infty}^{t_{k}^{-1}(v)} \frac{1}{2 \pi \sqrt{1-\theta^{2}}} \exp \left\{1+\frac{s^{2}-2 \theta s t+t^{2}}{k\left(1-\theta^{2}\right)}\right\}^{-\frac{k+2}{2}} d s d t$ & $(-1,1), \mathrm{k} \neq 0$ \\
\hline
\end{tabular}

In addition, the Ordinary Least Squares (OLS) minimum criterion and Akaike Information Criterion (AIC) were selected to test goodness of fit and determine the optimal copula function. The formulas of the inspection methods are:

$$
\begin{gathered}
\text { OLS }=\sqrt{\frac{1}{n-1} \sum_{\mathrm{i}=1}^{\mathrm{n}}\left(\mathrm{P}_{\mathrm{ei}}-\mathrm{P}_{\mathrm{i}}\right)^{2}} \\
\mathrm{AIC}=\operatorname{nln}\left[\frac{1}{\mathrm{n}-1} \sum_{\mathrm{i}=1}^{\mathrm{n}}\left(\mathrm{P}_{\mathrm{ei}}-\mathrm{P}_{\mathrm{i}}\right)^{2}\right]+2 l
\end{gathered}
$$

where, $\mathrm{P}_{\mathrm{ei}}$ is the joint empirical probability of two-dimensional variables, $\mathrm{P}_{\mathrm{i}}$ is the joint distribution value of the copula function, $n$ is the number of samples, and 1 is the number of parameters contained in the model. The smaller the values of OLS and AIC are, the closer the joint distribution probability value calculated by the copula function is to the empirical probability value, and the better the fitting effect is. 


\subsection{Joint return period calculation}

After selecting the optimal copula function, the return period of drought occurrence can be calculated. Joint return period is the reciprocal of the joint probability of two variables, which can be used to represent the risk of drought events. Salvadori and Michele (2004) proposed two return periods: 'or( $\square$ )' joint return period and 'and $(\cap)$ ' joint return period. Suppose two random variables are $\mathrm{X}$ and $\mathrm{Y}$, and the thresholds of $\mathrm{X}$ and $\mathrm{Y}$ are set to $\mathrm{x}$ and $\mathrm{y}$, respectively. ' $\square$ ' joint return period is the time interval in which at least one variable (X or $\mathrm{Y})$ is higher than the threshold $\left(\mathrm{T}_{(\mathrm{X}>\mathrm{x})} \square(\mathrm{Y}>\mathrm{y})\right.$ ); and ' $\cap$ ' joint return period refers to the time interval in which both $\mathrm{X}$ and $\mathrm{Y}$ exceeding their own thresholds $\left(\mathrm{T}_{(\mathrm{X}>\mathrm{x})} \cap(\mathrm{Y}>\mathrm{y})\right)$.

The socioeconomic drought duration and severity were tested against the gamma function, Weibull function, GEV function, lognormal function and log-logistic function for the best fit of the marginal distribution and to select the most suitable distribution function. After selecting the distribution function, the two marginal distributions were fitted using the copula, and the two drought return periods were calculated as follows (Guo et al. ,2019):

$$
\begin{gathered}
T_{(D>d) \cup(S>s)}=\frac{E(\Delta T)}{1-C\left(F_{D}(d), F_{S}(s)\right)} \\
T_{(D>d) \cap(S>s)}=\frac{E(\Delta T)}{\left.1-F_{D}(d)-F_{S}(s)\right)+C\left(F_{D}(d), F_{S}(s)\right)}
\end{gathered}
$$

where, $T_{(D>d) \square(S>s)}$ and $T_{(D>d) \cap(S>s)}$ are ' $\square$ ' and ' $\cap$ ' joint return period, respectively; $C$ represents the copula function; $C\left(F_{D}(d), F_{S}(s)\right)$ stands for the joint distributions of drought duration and intensity, which are combined using the copula function; $F_{D}(d)$ and $F_{I}(i)$ are the marginal distribution of drought duration and intensity, respectively; 
and $E(\Delta T)$ denotes the expected of drought events interval time, and is the sum of the average of drought duration and non-drought duration. Here drought interval was actually drought inter-arrival time.

\section{Results}

4.1 Socioeconomic drought events and their features 1985 to 2019 are shown in Figure 5 and Figure 6.

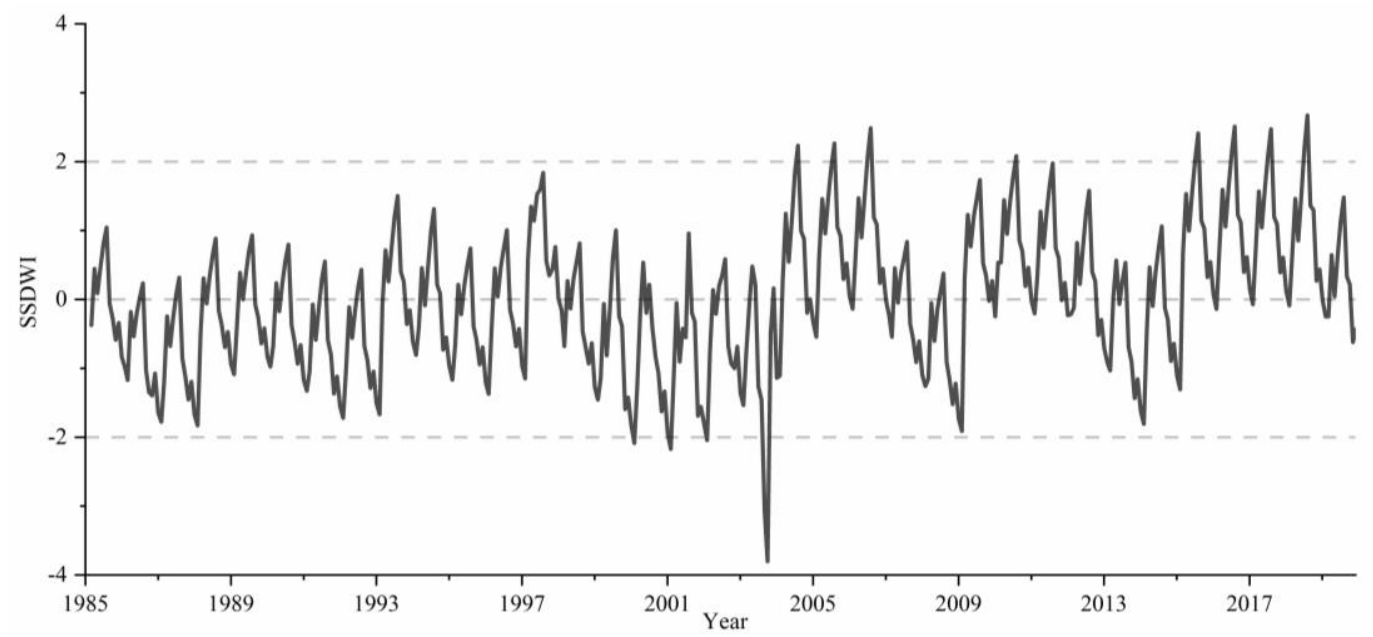

Fig. 5 Monthly SSDWI in the JJRB from 1985 to 2019 


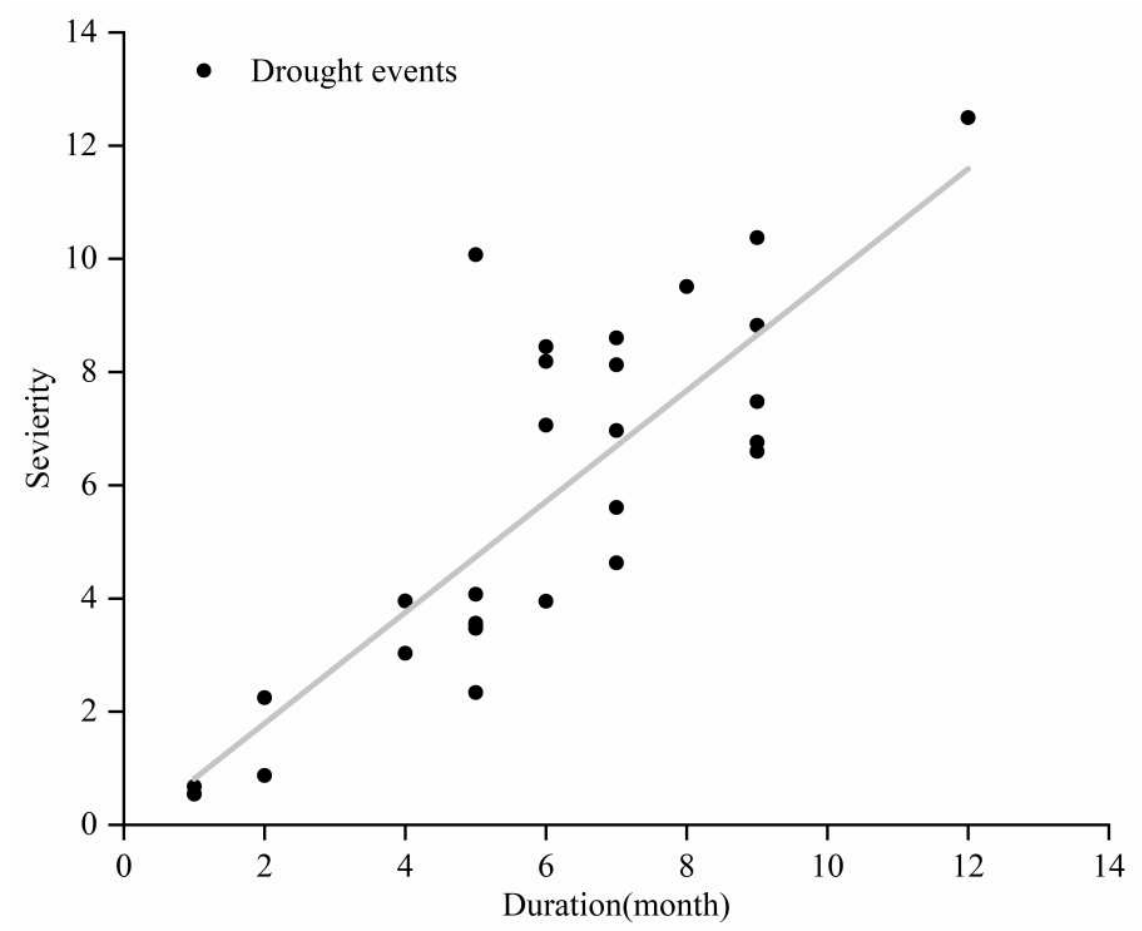

Fig. 6 Socioeconomic drought events during 1985-2019 in the JJRB

On the monthly scale, a total of 29 socioeconomic drought events occurred in the

JJRB over the 35 years study period, with an average duration of 6.16 months per were concentrated in 6-8 months, with few lasting less than 4 months or more than 10 months. Compared with meteorological drought and hydrological drought, the duration of socioeconomic drought tended to be longer.

On the seasonal scale (Fig. 7), it is considered that spring is January to March, summer is April to June, autumn is July to September, and winter is October to December. Winter and autumn generally had more frequent and more severe socioeconomic droughts. Socioeconomic droughts almost never occurred in summer due to the high rainfall, river flow, and high water supply rate during this season. 

while moderate droughts occurred in 1986,1991 and 2008.

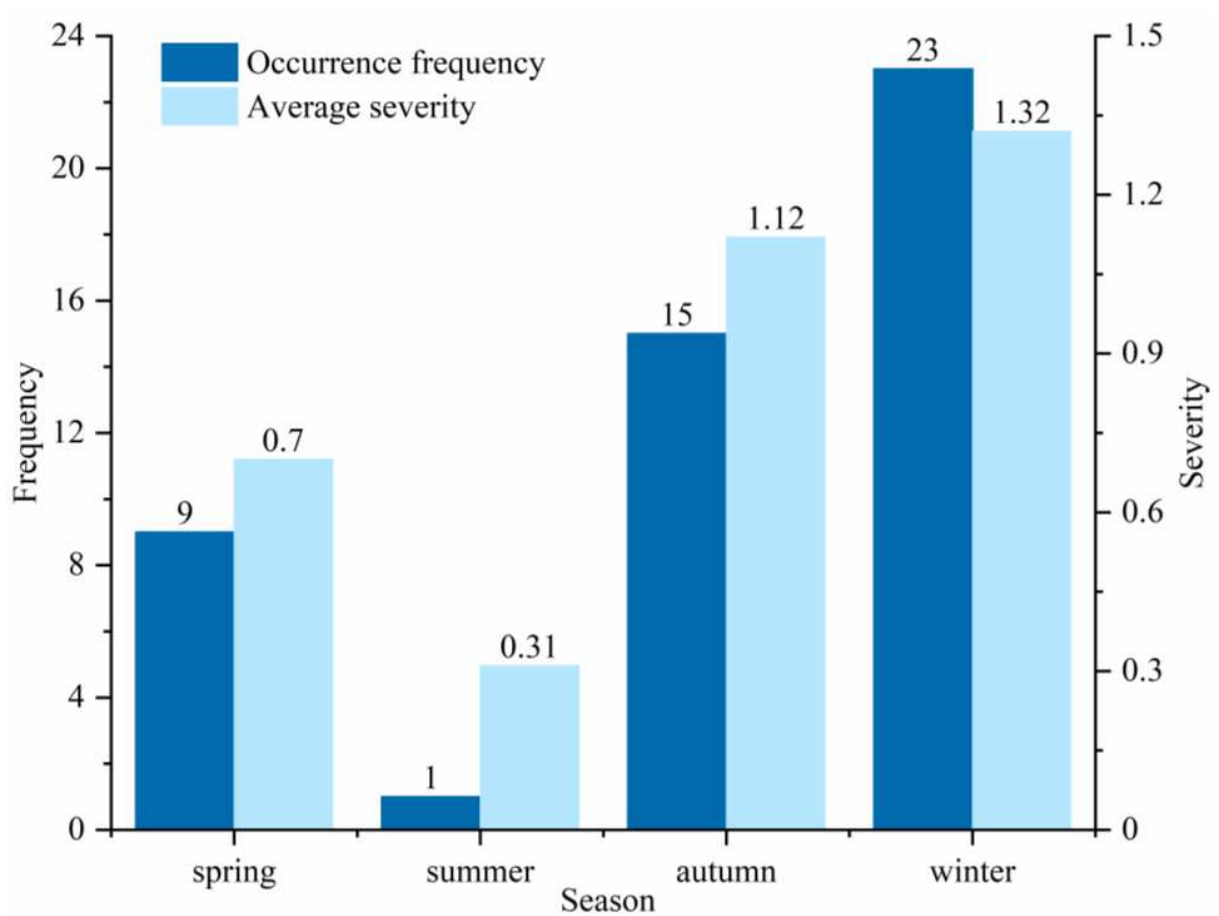

Fig. 7 Frequency and severity of socioeconomic drought in the JJRB in different seasons

\subsection{Marginal distribution fitting of drought duration and severity}

In order to accurately determine the critical values for different grades of drought events, the Weibull distribution, GEV distribution, normal distribution, logistic distribution, log-logistic distribution and generalized Pareto (GP) distribution were used to fit the duration and severity of droughts. The distribution with the best goodness of fit was selected by K-S test. All distributions met the 0.05 significance threshold, and the results are shown in Table 4. The empirical and theoretical distributions are shown in Figure 8. Table 4 shows that the best fitting distributions for drought duration and severity were the logistic and GP distributions, respectively. Figure 8 further 

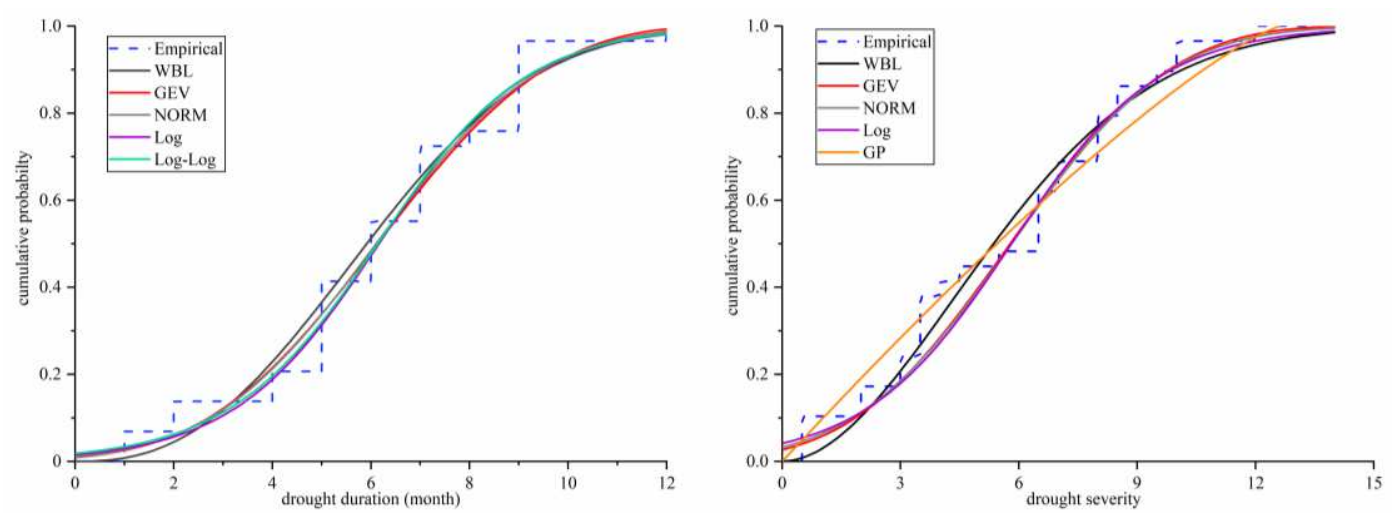

Fig. 8 Empirical and theoretical CDFs fitted to drought duration and severity

Table 4 K-S test of drought duration and severity marginal distribution fitting

\begin{tabular}{ccccccc}
\hline K-S Test value & WBL & GEV & NORM & Log & Log-Log & GP \\
\hline Duration & 0.4156 & 0.6482 & 0.6553 & 0.8093 & 0.7977 & 0.0707 \\
Severity & 0.4128 & 0.7473 & 0.7232 & 0.6403 & 0.6050 & 0.7515 \\
\hline
\end{tabular}
drought.

Table 5 Gradation of socioeconomic drought events according to duration and intensity

\begin{tabular}{ccc}
\hline Socioeconomic drought event & Duration & Severity \\
\hline Slight drought & $<4$ months & $<3$ \\
Moderate drought & $4 \sim 7$ months & $3 \sim 7$ \\
Severe drought & $7 \sim 10$ months & $7 \sim 10$ \\
Extreme drought & $>10$ months & $>10$ \\
\hline
\end{tabular}




\begin{tabular}{cccccc}
\hline Selection basis & Clayton & Frank & Gumbel & gaussian & $\mathrm{t}$ \\
\hline AIC & -15.58 & -18.28 & -17.06 & -20.25 & -20.99 \\
OLS & 0.0541 & 0.0516 & 0.0527 & 0.0499 & 0.0492 \\
\hline
\end{tabular}

\subsection{Selection of the optimal copula function}

According to the optimal distribution of drought duration and severity in Section 4.2, the Log distribution and GP distribution were selected to fit the marginal distribution of drought duration and severity, respectively. Figure 6 shows a significant positive correlation between drought duration and severity. The Kendall and Spearman rank correlation coefficients between drought duration and severity were 0.62 and 0.76 , respectively. Therefore, the copula function can be used to construct the joint probability distributions of drought duration and severity. The copula parameter $\theta$ was estimated using the maximum likelihood method. AIC and OLS were used as parameters to select the best fitting copula. The results are shown in Table 6 .

It was obvious that the t-copula was the most suitable copula because it had the smallest AIC and OLS values (Table 6). These results indicated that the t-copula had the best fit for drought duration and severity. Therefore, the t-copula was chosen to construct the drought risk model in this study. The resulting joint distributions and contours of drought duration and severity are shown in Figure 9 and Figure 10, respectively. 


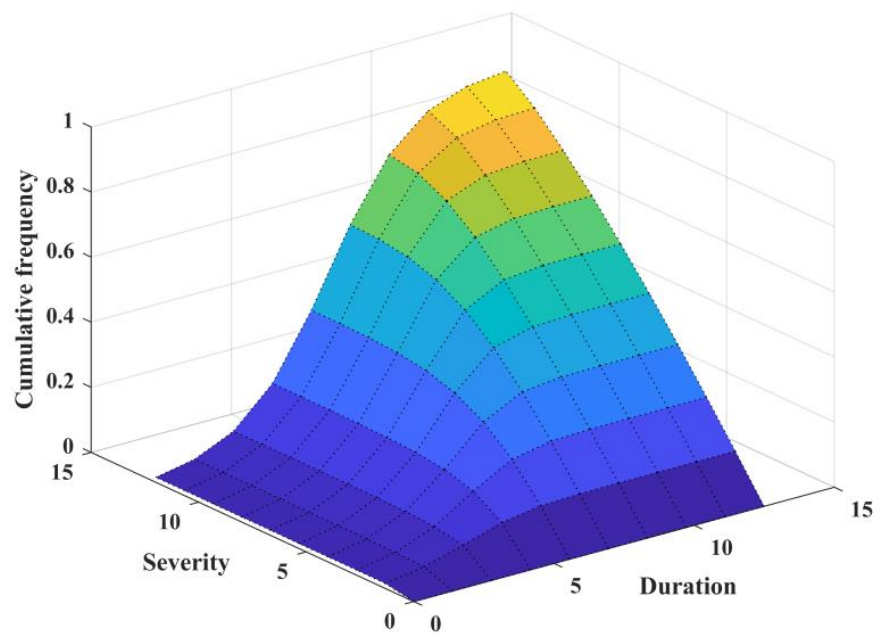

Fig. 9 Cumulative distribution diagram of socioeconomic drought duration and severity in the JJRB

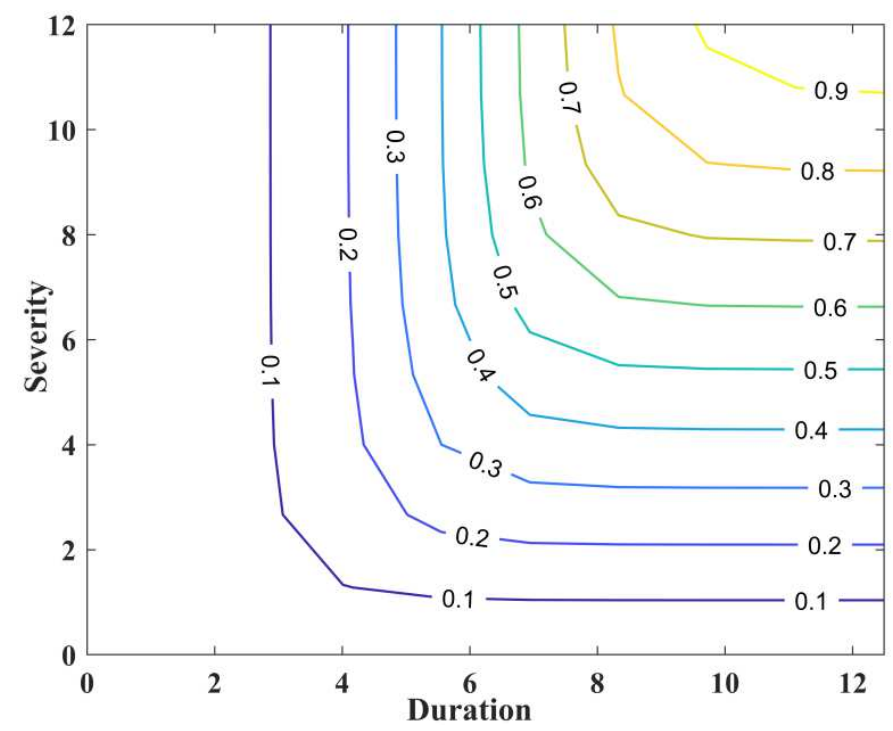

Fig. 10 Contours diagram of socioeconomic drought duration and severity in the JJRB

\subsection{Calculation of drought return periods of different grades}

After the copula function of drought duration and severity is optimally fitted, the joint return periods (' $U$ ' and ' $\cap$ ') in the two cases were calculated to characterize the socioeconomic drought in the JJRB. The results are shown in Figure 11, and the joint return periods of different grades of socioeconomic droughts are shown in Table 3. 
Obviously, the possibility of socioeconomic drought with return period ' $U$ ' is higher than that with return period ' $\cap$ '. With increasing drought duration and severity, the joint return periods of ' $U$ ' and ' $\cap$ ' increased. The joint return periods of ' $U$ ' and ' $\cap$ ' under moderate drought conditions were 8.81 years and 10.81 years, respectively. while those under severe drought conditions were 16.49 and 26.44 years, respectively. Furthermore, the joint return periods of ' $U$ ' and ' $\cap$ ' under extreme drought conditions were 41.68 years and 91.13 years, respectively.

Table 7 Joint return periods for different grades of socioeconomic drought in the JJRB

\begin{tabular}{ccc}
\hline Drought scenarios & $‘ \cup$ 'joint return period (year) & $' \cap$ 'joint return period (year) \\
\hline Moderate drought & 8.81 & 10.81 \\
Severe drought & 16.49 & 26.44 \\
Extreme drought & 41.68 & 91.13 \\
\hline
\end{tabular}
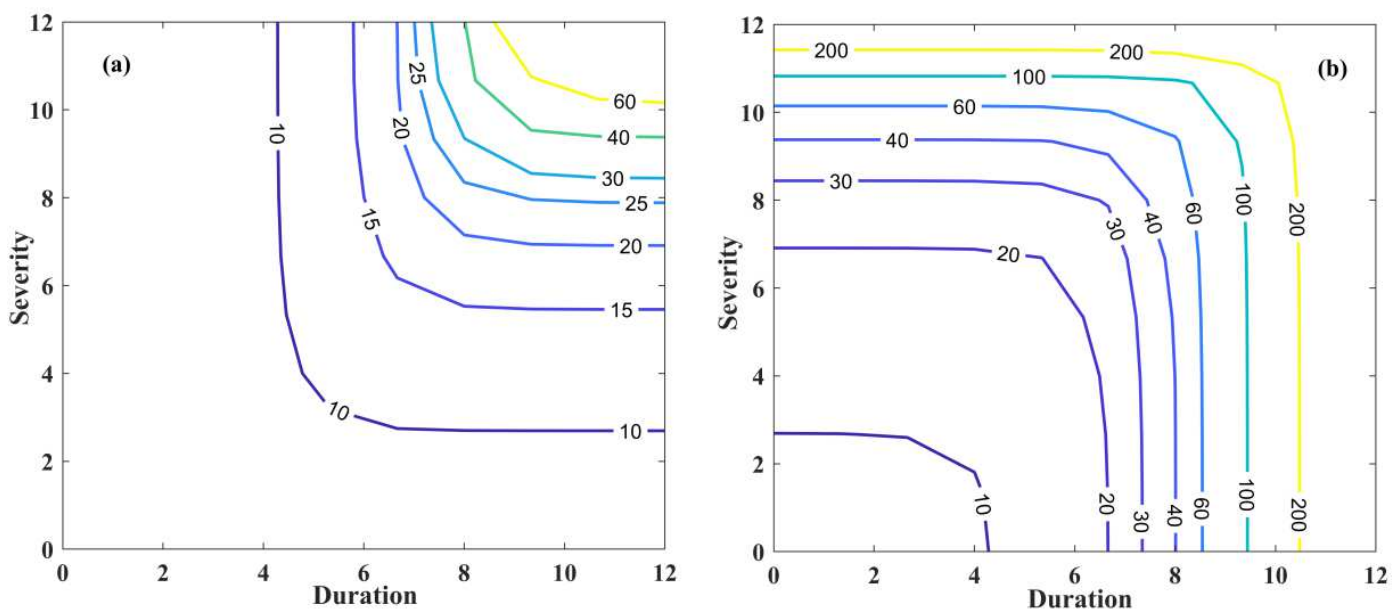

Fig. 11 ' $\cup$ ' (a) and ' $\cap$ '

(b) joint return period of drought duration and severity

\section{Discussion}


of drought. The abnormal shortage of rainfall leads to reduced river runoff and water shortages in human life and production. In order to explore the relationship between meteorological, hydrological and socioeconomic drought, the data of rainfall, temperature and river runoff data measured in the JJRB were used to calculate SPEI and human social systems, then a socioeconomic drought occurs. Therefore,

(Vicente-Serrano et al.,2010) and SDI (Nalbantis I et al.,2009), and characterize meteorological and hydrological drought from 1985 to 2019. The relationships among SPEI, SDI, and SSDWI indices at monthly, seasonal, and annual scales were analyzed using Pearson correlation coefficient (significance level of 0.01). As shown in Table 8, the three droughts types were most strongly correlated at the 12-month scale. Compared with meteorological drought, hydrological drought was more closely related to socioeconomic drought. Therefore, it is appropriate to use flow deficit as a measure of socioeconomic drought. Sufficient river runoff volume is important in maintaining water quality, preventing saltwater intrusion, ensuring river ecological health, facilitating ship navigation and supplying water intake outside the river. Therefore, a river needs to meet the requirements of minimum ecological flow, navigable flow and basin water demand requirements. When the river flow is abnormally low, under the premise of prioritizing ecological flow and navigable flow, meeting the water demands outside the river (i.e., agricultural demands) is often impossible. In these scenarios, there is an imbalance between water supply and demand between the natural systems hydrological drought is the most direct causes of socioeconomic drought, and the 
relationship between them is relatively close.

Table 8 Pearson correlation coefficients among the three drought indices

\begin{tabular}{cccc}
\hline Scale & SPEI and SDI & SPEI and SSDWI & SDI and SSDWI \\
\hline Month & 0.5231 & 0.2811 & 0.5097 \\
Season & 0.5984 & 0.3579 & 0.6381 \\
Year & 0.6437 & 0.5338 & 0.7682 \\
\hline
\end{tabular}

\subsection{Trends of socioeconomic, hydrological and meteorological drought}

As shown in Figure 12, SSDWI-12 had an increasing trend since 1985, and its value was $0.067<0.1$ after passing the Pettitt test, This indicated that there was a mutation point in the index sequence at some time in the 35 year study period, and the mutation point was 2008. The mean value of SSDWI before 2008 was -0.37 , but 0.76 afterwards, indicating that the risk of socioeconomic drought in the JJRB had been significantly reduced. The frequency and severity of socioeconomic drought in recent years have significantly declined. Similarly, due to the high correlation between hydrological drought and socioeconomic drought, the change in 2008 was reflected in hydrological drought as well. The average SDI was 0.35 before 2008 and 0.51 after, indicating that the hydrological drought occurrence and severity had been significantly improved, and the river runoff in the dry season was more reliable. However, SPEI did not change significantly, with mean values before and after 2008 of -0.15 and 0.13 , respectively, indicating that there was no significant climate change in the JJRB in the past 35 years. 

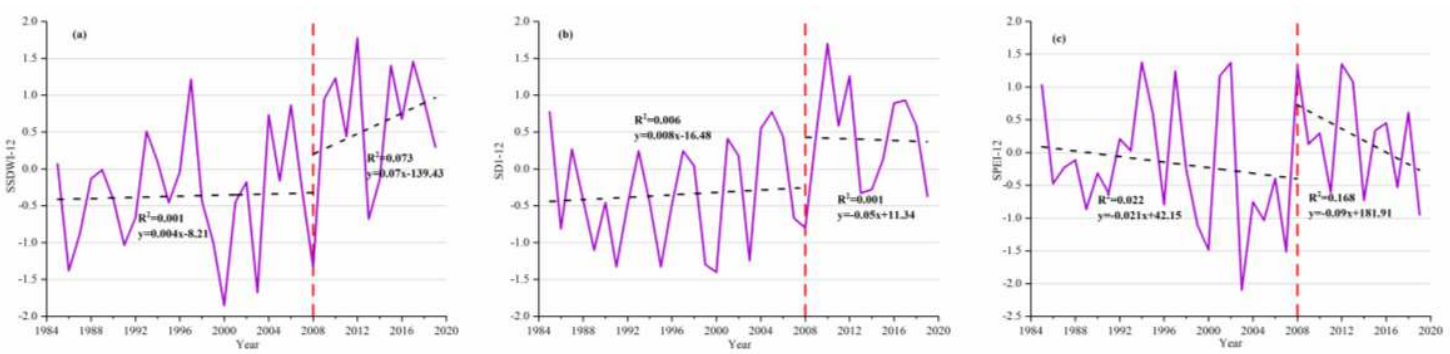

Fig. 12 Trends of socioeconomic drought (a), hydrological drought (b) and meteorological drought(c)

\subsection{Possible causes}

Among the previous socioeconomic drought evaluation indicators, reservoirs have been identified as indispensable in ensuring sufficient river runoff and water supply in the basin during dry periods. Gaozhou Reservoir is also the most important water storage project in the JJRB. Under the assumption that there has been no remarkable change in climate in recent years, reservoir operation in the basin is the likely reason for the obvious alleviation of hydrological and socioeconomic drought since 2008 . Therefore, the daily average discharge of Gaozhou Reservoir in spring, autumn and winter (mainly used for flood management in summer) from 1985 to 2019 was analyzed. The results in Figure 13 show that, the discharge of the reservoir has been increasing, and the increase has been more pronounced since 2008. The mean discharge before and after 2008 were $62.3 \mathrm{~m}^{3} / \mathrm{s}$ and $117.9 \mathrm{~m}^{3} / \mathrm{s}$, respectively. This was, due to the improved operation and utilization of the reservoir by the basin management department that the runoff of the river during the dry season is guaranteed, and also include the normal water supply and the normal water intake of the water users, thus significantly reduces the frequency and severity of hydrological drought and socioeconomic drought. 


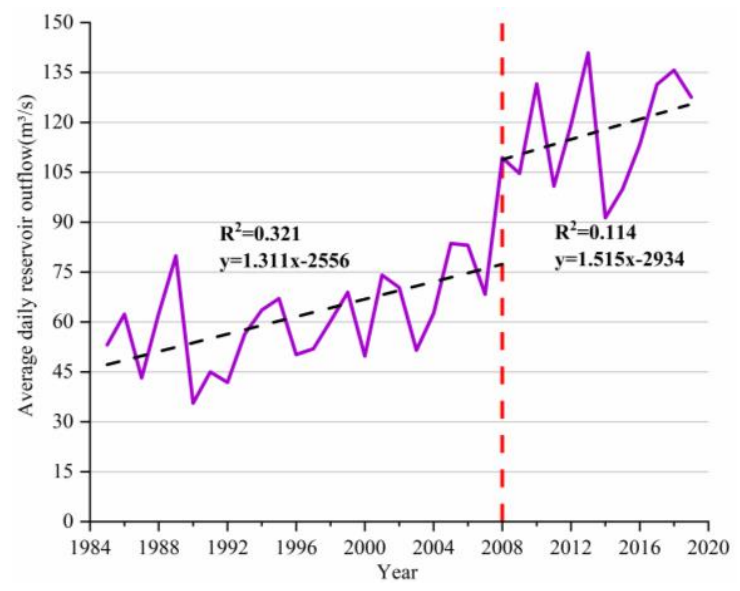

Fig. 13 Daily average outflow of Gaozhou Reservoir in spring, autumn and winter from 1985 to 2019

\section{Conclusions}

In this paper, a new indicator for characterizing socioeconomic drought, the standardized supply and demand water index was proposed. Taking the JJRB as an example, the characteristics of socioeconomic drought were discussed without considering the resilience. The occurrence of drought along different time scales and the characteristics of drought duration and severity were analyzed using copula functions. Then the return periods of socioeconomic drought were calculated. The trends of droughts in the basin and possible underlying causes were also discussed. The main conclusions were as follows:

(1) SSDWI was suited to characterizing the socioeconomic drought in the JJRB. There were 29 socioeconomic drought events in the basin from 1985 to 2019, with an average duration of 6.16 months and an average severity of 5.82. Socioeconomic droughts mainly occur in autumn and winter, which also experienced more serious drought than other seasons;

(2) In JJRB, the joint return periods of ' $U$ ' and ' ' for moderate drought, severe 
drought and extreme drought were 8.81a and 10.81a, 16.49a and 26.44a and 41.68a and 91.13a, respectively;

(3) The risk of socioeconomic drought and hydrological drought in the JJRB has dropped significantly since 2008 due to the increased outflow from the Gaozhou Reservoir. The reasonable operation of the reservoir plays an important role in alleviating hydrological drought and socioeconomic drought in the basin.

The research results of this paper provide a new perspective for the identification and assessment of socioeconomic droughts in a changing environments. The findings of this paper will be helpful in the management of local water resources and the prevention of socioeconomic drought. However, there are still many problems to be solved, such as how to calculate the monthly water supply and demand more finely and accurately, which part of the supply and demand chain has the greatest impact on socioeconomic drought, and how reservoirs and water supply projects work together to minimize the risk of socioeconomic drought, etc. These are the directions for further research.

\section{Acknowledgments}

The research is financially supported by National Natural Science Foundation of China (Grant No. U1911204 , 51861125203), National Key R\&D Program of China (2017YFC0405900), the Project for Creative Research from Guangdong Water Resources Department (Grant No. 2018, 2020).

Authors' Contributions J.W. Zhou: Conceptualization, Investigation, Methodology, Formal analysis, Writing - original draft. X.H. Chen: Supervision, Data curation, 
512 Funding acquisition, Writing - review \& editing. C. Xu\&W. Pan: Writing - review \&

513 editing.

514 Data Availability The data has been obtained through surveys and Guangdong

515 Hydrographic Bureau. If necessary, the database could be made available.

\section{Declaration of Competing Interest}

517 The authors declared that they have no conflicts of interest to this work.

\section{$518 \quad$ References}

519 Abramowitz, M. , Stegun, I. A. , \& Miller, D. . (1965). Handbook of mathematical functions with formulas, graphs and mathematical tables (national bureau of standards applied mathematics series no. 55). Journal of Applied Mechanics, 32(1), 239.

Aherne, J., Larssen, T., Cosby, B.J., Dillon, P.J., 2006. Climate variability and forecasting surface water recovery from acidification: modelling droughtinduced sulphate release from wetlands. Sci. Total Environ. 365, 186-199.

Ahn, S.R., Jeong, J.H., Kim, S.J., 2016. Assessing drought threats to agricultural water supplies under climate change by combining the SWAT and MODSIM models for the Geum River basin, South Korea. Hydrol. Sci. J. 61 (15), 2740-2753.

American Meteorological Society (AMS) Statement. 2004. AMS statement on meteorological drought. Bulletin of the American Meteorological Society, 85, $771-773$.

Arab, D. , Elyasi, A. , Far, H. T. , \& Karamouz, M. . (2010). Developing an Integrated Drought Monitoring System Based on Socioeconomic Drought in a 

Resources Congress (pp.2754-2761).

Bai T, Wu L, Chang J, Huang Q. 2015. Multi-objective optimal operation model of cascade reservoirs and its application on water and sediment regulation. Water Resour Manage.29(8):2751-2770.

Boisson, A., Baisset, M., Alazard, M., Perrin, J., Villesseche, D., Dewandel, B., et al. (2014). Comparison of surface and groundwater balance approaches in the evaluation of managed aquifer recharge structures: Case of a percolation tank in a crystalline aquifer in India. Journal of Hydrology, 519, 1620-1633. https://doi.org/10.1016/j.jhydrol.2014.09.022.

Cammalleri, C. , Jürgen Vogt, \& Salamon, P. . (2017). Development of an operational low-flow index for hydrological drought monitoring over europe. International Association of Scientific Hydrology Bulletin, 62(3), 346-358.

Dinar, A. , \& Mendelsohn, R. . (2011). Handbook on climate change and agriculture. Robert Mendelsohn.

Eklund, L., \& Seaquist, J. (2015). Meteorological, agricultural and socioeconomic drought in the Duhok Governorate, Iraqi Kurdistan.Natural Hazards, 76(1), 421-441. https://doi.org/10.1007/s11069-014-1504-x.

Fang W, Huang Q, Huang S, Yang J, Meng E, Li Y. 2017. Optimal sizing of utility-scale photovoltaic power generation complementarily operating with hydropower: a case study of the world's largest hydro-photovoltaic plant. Energy Convers Manage. 136:161-172. 
Fang W, Huang S, Huang G, Huang Q, Wang H, Wangal L, Zhang Y, Li P, Ma L. 2019a.Copulas-based risk analysis for inter-seasonal combinations of wet and dry conditions under a changing climate. Int J Climatol. doi: 10.1002/joc.5929.

Fekete, B. M. , CJ Vörösmarty, \& Grabs, W. . (2000). Global, composite runoff fields based on observed river discharge and simulated water balances. Grdc Rep Global Runoff Data.

Guo, Y., Huang, S. Z., Huang, Q., Wang, H., Wang, L., \& Fang, W. (2019b). Copulasbased bivariate socioeconomic drought dynamic risk assessment in a changing environment. Journal of Hydrology, 575, 1052-1064. https://doi.org/10.1016/j.jhydrol.2019.06.010

Hanson, P.J., Weltzin, J.F., 2000. Drought disturbance from climate change: response of United States forests. Sci. Total Environ. 262 (3), 205-220.

Hayes, M. , DA Wilhite, Svobo Da , M. , \& Trnka, M. . (2011). Investigating the connections between climate change, drought and agricultural production.

Hirabayashi, Y., Kanae, S., Emori, S., Oki, T., Kimoto, M., 2008. Global projections of changing risks of floods and droughts in a changing climate. Hydrol. Sci. J. 53 (4), 754-772.

Huang, S. Z., Huang, Q., Leng, G. Y., \& Liu, S. Y. (2016). A nonparametric multivariate standardized drought index for characterizing socioeconomic drought: A case study in the Heihe River Basin. Journal of Hydrology, 542, 875-883. https://doi.org/10.1016/j.jhydrol.2016.09.059.

I. Nalbantis and G. Tsakiris. Assessment of Hydrological Drought Revisited[J]. Water 
Ingram, J., \& Bartels, D. (1996). The molecular basis of dehydration tolerance in plants. Annual Review of Plant Physiology and Plant Molecular Biology, 47(1), 377403. https://doi.org/10.1146/annurev.arplant.47.1.377.

Kogan, F.N., 1995. Droughts of the late 1980s in the United States as derived from NOAA polar-orbiting satellite data. American Meteorological Society]->Bull. Am. Meteorol.Soc. 76, 655-668.

Kunkel, K.E., 2003. North American trends in extreme precipitation. Nature Hazards 29(2), 291-305. https://doi.org/10.1023/A:1023694115864.

Liu, S. N., Shi, H. Y., Niu, J., Chen, J., \& Kuang, X. X. (2020). Assessing future socioeconomic drought events under a changing climate over the Pearl River basin in South China. Journal of Hydrology: Regional Studies, 30, 100700.

Liu, S. , Shi, H. , \& Sivakumar, B. . (2020). Socioeconomic drought under growing population and changing climate: a new index considering the resilience of a regional water resources system. Journal of Geophysical Research Atmospheres, 125(15), e2020JD033005.

L. P. H. van Beek and Yoshihide Wada and Marc F. P. Bierkens. Global monthly water stress: 1. Water balance and water availability[J]. Water Resources Research, 2011, 47(7)

Madani, K. (2014), Water management in Iran: What is causing the looming crisis?, J. Environ. Stud.Sci., 4(4), 315-328.

Mckee, T. B. , Doesken, N. J. , \& Kleist, J. . (1993). The Relationship of Drought 
601

602

603

604

605

606

Mehran, A., Mazdiyasni, O., \& AghaKouchak, A. (2015). A hybrid framework for assessing socioeconomic drought: Linking climate variability, local resilience, and demand. Journal of Geophysical Research: Atmospheres, 120, 7520-7533. https://doi.org/10.1002/2015JD023147

Mishra, A.K., Singh, V.P., 2010. A review of drought concepts. J. Hydrol. 391, 202216.

Montanari, A. (2015), Debates-Perspectives on socio-hydrology: Introduction, Water Resour. Res.,51, 4768-4769, doi:10.1002/2015WR017430.

Palmer, W. C.: 1965, Meteorological Drought, U.S. Weather Bureau Research Paper No. 45. U.S.Dept. of Commerce, Washington, D.C.

Paradis, C. J., Johnson, R. H., Tigar, A. D., Sauer, K. B., Marina, O. C., \& Reimus, P. W. (2020). Field experiments of surface water to groundwater recharge to characterize the mobility of uranium and vanadium at a former mill tailing site. Journal of Contaminant Hydrology, 229, 103581. https://doi.org/10.1016/j.jconhyd.2019.103581

Piao, S. L., Ciais, P., \& Huang, Y. (2010). The impacts of climate change on water resources and agriculture in China. Nature, 467(7311),43-51. https://doi.org/10.1038/nature09364

Ren, K., Huang, S.Z., Huang, Q., et al., 2019. A nature-based reservoir optimization model for resolving the conflict in human water demand and riverine ecosystem protection.J. Clean. Prod. 231 (10), 406-418. 
Shafer, B. A. , \& Dezman, L. E. . (1982). Development of a Surface Water Supply Index (SWSI) to assess the severity of drought conditions in snowpack runoff areas.

Shao, W. W., Yang, D. W., Hu, H. P., \& Sanbongi, K. (2009). Water resources allocation considering the water use flexible limit to water shortage - A case study in the Yellow River Basin of China. Water Resources Management, 23(5), 869-880. https://doi.org/10.1007/ s11269-008-9304-2

Shi, H. Y., Chen, J., Wang, K. Y., \& Niu, J. (2018). A new method and a new index for identifying socioeconomic drought events under climate change: A case study of the East River basin in China. Science of the Total Environment, 616, 363375.

Shiklomanov, I. A. , Shiklomanov, A. I. , Lammers, R. B. , Peterson, B. J. , \& Vorosmarty, C. J. . (2000). The Dynamics of River Water Inflow to the Arctic Ocean. Springer Netherlands.

Shukla, S., Wood, A.W., 2008. Use of a standardized runoff index for characterizing hydrologic drought. Geophys. Res. Lett. 35 (2), L02405.

Sivapalan, M. (2015), Debates-Perspectives on sociohydrology: Changing water systems and the "tyranny of small problems"-Sociohydrology,Water Resour. Res., 51, 4795-4805,doi:10.1002/2015WR017080.

Stoll, S., H. J. Hendricks Franssen, M. Butts, and W. Kinzelbach (2011), Analysis of the impact of climate change on groundwater related hydrological fluxes: A multi-model approach including different downscaling methods, Hydrol. Earth Syst. Sci., 15(1), 21-38. 
Tietjen, B., Schlaepfer, D. R., Bradford, J. B., Lauenroth, W. K., Hall, S. A., Duniway, M. C., et al. (2017). Climate change-induced vegetation shifts lead to more ecological droughts despite projected rainfall increases in many global temperate drylands. Global Change Biology,23(7), 2743-2754. https://doi.org/10.1111/gcb.13598

Trenberth, K. (2001), Climate variability and global warming, Science, 293(5527), 4849.

Tsanis, I., \& Tapoglou, E. (2019). Winter North Atlantic Oscillation impact on European precipitation and drought under climate change.Theoretical and Applied Climatology, 135(1-2), 323-330. https://doi.org/10.1007/s00704-018-2379-7

Tu, X.J., Wu, H.O., Singh, V.P., et al., 2018. Multivariate design of socioeconomic drought and impact of water reservoirs. J. Hydrol. 566, 192-204.

Vandenberghe, S., Verhoest, N.E.C., Onof, C., De Baets, B., 2011. A comparative copula based bivariate frequency analysis of observed and simulated storm events: a case study on Bartlett Lewis modeled rainfall. Water Resour. Res. 47, 197-203.

Vicente-Serrano, S. M. , S Beguería, \& JI López-Moreno. (2010). A multiscalar drought index sensitive to global warming: the standardized precipitation evapotranspiration index. Journal of Climate, 23(7), 1696-1718.

Vicuna, S., Gironas, J., Meza, F. J., Cruzat, M. L., Jelinek, M., Bustos, E., et al. (2013). Exploring possible connections between hydrological extreme events and climate change in central south Chile. Hydrological Sciences Journal, 58(8), 
Vogel, R. M., U. Lall, X. Cai, B. Rajagopalan, P. Weiskel, R. P. Hooper, and N. C. Matalas (2015), Hydrology: The interdisciplinary science of water,Water Resour. Res., 51, 4409-4430, doi:10.1002/2015WR017049.

Vörösmarty, C.J., Sahagian, D., 2000. Anthropogenic disturbance of the terrestrial water cycle. BioScience 50 (9), 753-765.

Wada, Y. , Beek, L. , D Viviroli, HH Dürr, \& Bierkens, M. . (2011). Global monthly water stress: 2. water demand and severity of water stress. Water Resources Research, 47(7).

Wheater, H. S., and P. Gober (2015), Water security and the science agenda, Water Resour. Res., 51, doi:10.1002/2015WR016892.

Wilhite, D.A., Glantz, M.H., 1985. Understanding the drought phenomenon: the role of definitions. Water Int. 10, 111-120.

Wilhite, D. A. . (2000). Drought : a global assessment. Routledge.

Organization, W. M. . (2006). Drought monitoring and early warning : concepts, progress and future challenges. WMO, 1006.

Yevjevich, V. . (1967). An objective approach to definitions and investigations of continental hydrologic droughts.

Yoo, J., Kim, D., Kim, H., Kim, T.W., 2016. Application of copula functions to construct confidence intervals of bivariate drought frequency curve. J. Hydro Environ. Res. 11,113-122.

Zhang, S., Gao, H., Naz, B.S., 2014b. Monitoring reservoir storage in South Asia from 
multisatellite remote sensing. Water Resour. Res. 50, 8927-8943.

689

690

691

692

693

694

695

696

697

698

699

Zhao, M. , Huang, S. , Huang, Q. , Wang, H. , Leng, G. , \& Xie, Y. . (2019). Assessing socio-economic drought evolution characteristics and their possible meteorological driving force. Geomatics Natural Hazards \& Risk, 10(1), 10841101.

Zhou, Z. Q., Shi, H. Y., Fu, Q., Li, T. X., Gan, T. Y., Liu, S. N., \& Liu, K. (2020a). Is the cold region in Northeast China still getting warmer under climate change impact?

Atmospheric

Research, 237,104864 . https://doi.org/10.1016/j.atmosres.2020.104864

Zhou, Z. Q., Shi, H. Y., Fu, Q., Li, T. X., Gan, T. Y., \& Liu, S. N. (2020b). Assessing spatiotemporal characteristics of drought and its effects on climate-induced yield of maize in Northeast China. Journal of Hydrology, 588, 125097. https://doi.org/10.1016/j.jhydrol.2020.125097

Zseleczky, L. , \& Yosef, S. . (2014). Are shocks really increasing? A selective review of the global frequency, severity, scope, and impact of five types of shocks. Conference Papers. International Food Policy Research Institute (IFPRI). 